\title{
THE ACT OF BETROTHAL ACCORDING TO LITURGICAL COLLECTION NO. 66, KEPT IN THE SCIENTIFIC ARCHIVE OF BAS
}

\author{
Galya Todorova \\ gachebg@abv.bg
}

Scientific Archive at the Bulgarian Academy of Sciences, Sofia, Bulgaria

\begin{abstract}
Liturgical corpus No. 66 is stored in the Scientific Archives - BAS (collection X) and it is from the XVI - XVII centuries. This the last stage of development of the engagement of the bridegroom, which is found in separate manuscripts, distinguished as a liturgy rank. The Serbian redaction presents a relatively late revision of sequence the engagement. Relations between the participants in the subsequent marriage are resolved (controlled) through this action performed within the boundaries of families.
\end{abstract}

Keywords: Betrothal; Manuscript; Ritual; Prayer; Marriage

\section{ЧИНЪТ ОБРУЧЕНИЕ СПОРЕА БОГОСАУЖЕБЕН СБОРНИК №66, СЪХРАНЯВАН В НА - БАН}

Галя Тодорова

Научен архив на Българска акалемия на науките, София, България

Резюме: Богослужебен сборник № 66 е съхраняван в НА БАН (сбирка X) и е от XVI - XVII в. т. е. това е послеАният етап от развитието на чина на обручение, който се среща в отлелни ръкописи, обособен като самостоятелно послеАование. Преписът е сръбска реАакция и преАставя сравнително късна реАакция на чинопоследованието обручение. Отношенията межАу участниците в последвалия брак са решавани (контролирани) чрез това Аействие извършвано в границата на семействата. брак

КАючови Ауми: голеж (обручение); рькопис; обред; молитва;

Цьрковният голеж се среща пол различни найменования като: армосвание, обручвание или голеж. Според каноничното право той е почти равен с венчанието. От тук и възрастта за венчание трябвало $а$ а бъле също законосьобразна. За това слеляла Цьрквата още от старо време (Baldzhiev, 1891: р. 183). Най - ранната възраст за встьпване на голежен акт е била 9 голини за жената и 12 голини за мъжа (Nikolchev, 2007). 
Това е възрастта, когато те са вече узрели и могат да чувствуват полови влечения и за това са способни Аа скАючват т. нар. годежни Аоговори. Самият годежен акт, ако е сключен на тази възраст се е смятал за Аействителен, а пол нея - нищожен (Baldzhiev, 1891: р. 184). Всички брачни обреди преАставляват последователен реА и се разделят на три отАелни Аействия - сватуване, годеж и сватба. СпореА Ө. К. Волковь (Volkov, 1891: р. 216) тези Аействия са повторение на еАин и сьщи ритуал и се обясняват с желанието обредьт и веселбата $\Delta а$ продьлжат по - дьлго време (Volov, р. 1891). Годежьт е сьпьтстван от няколко Аействия. При него се симулирали неприятелски отношения межау сватовете, които се свьршвали с мирно откупуване на невестата, размяна на хлябове, обрела на сялането и залружното ялене. После невястината майка постилала за Авамата постеля т. е. позволява се орактически съжителство (Volkov, 1891: р. 217). СпореА народните възглеАи взаимното съгласие на голеника и годеницата не винаги е елнозначно. Жената (момата) е без особена гласност. Само при случаите на "продажба" и т. нар. "натурвание" се е проявявала нейната воля. В случай на "отвличане" или "измамване" - решаваща е волята на мъжа, а когато има "пролажба" на девойката, то от значение е волята на бащата. Взаимното сьгасие на Авамата канАилати се е проявява^о при "пристанката" (Baldzhiev, 1891: р. 190). За Цьрквата е необхолимо взаимно сьгласие на желаещите, за ла се бракосьчетаят. Необхолимо е и Авама свилетели, за да бъле законно и Аействително бракосьчетанието. От различните събори научаваме, какви са разпоредбите за сгодените. Анкирския поместен събор (314 г.),

Правило 11 определя на годениците да бъдат върнати сгодените за тях Аевици, макар и вече $а$ с са обезчестени от похитителите си² $^{2}$

\footnotetext{
${ }^{1}$ т. е. ако енно от бракосъчетаващите се мица е било насилено.

2 Анкирски поместен събор, Правило 11, гласи: „Определяме: Аевици, които са били сгодени за някои и слеА това са били отвлечени, нека бъАат върнати на годениците им, макар и да са бими обезчестени от похитителите си."
} 
Същия събор описва епитимия, когато годеник разтлел сестрата на своята годеница и тя СлеА това е посегнала на своя живот ${ }^{3}$.

С поставновление № 98 от Шестия Вселенски събор (Трулски) (681г.), се осъжАа за прелюболействие този, който е взел за брачно съжителство сгодена за Аруг ${ }^{4}$. СпореА 67 правило на св. апостоли - ако някой изнасили несгодена Аевица е Альжен $а$ я вземе макар тя $\Delta \mathrm{a}$ е сиромахкиня. ${ }^{5}$ Сгодените моми са приемани като такива наА който годеникът вече има право на гласност за техните действия. Това свидетелстват епитимиите на св. Василий от II Каноническо послание АО Амфилохий Иконийски, където сгодените и несгодени жени са с различен статус ${ }^{6}$. Прави^о 69 на същия автор потвържАава това и определя забрана, която се отнася до четеца и иподякона, които се

3 Анкирски поместен събор, Правило 25, гласи: Някой се сгоди^ за Аевица, но преАи Аа встьпи в брачен съюз с нея, разтлел сестра й, от което тя забременяла, после се оженил за годеницата си, а разтлената се обесила. Заповядваме: виновниците $\Delta a$ се Аопуснат $а$ а стоят на молитва С верните в продьлжение на Аесет години, прекарани в установените степени на покаянието.

${ }^{4}$ Шести Вселенски събор (680/681г.), Правило 98, гласи: „Който взима за брачно съжителство сгодена за Аруг, когато годеникьт ѝ е още жив, нека се наказва като прелюболеец."

5 Правила на Св. Апостоли, Правило 67, гласи: Ако някой изнасили несгодена Аевица, Аа бъде отльчен от църковно общение и в никой случай $А$ не му се

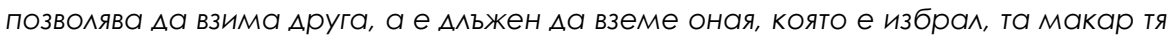
$\triangle$ а е и сиромахкиня.

${ }^{6}$ Из: ІІ Каноническо послание на св. Василий Ао Аморилохий Иконийски. Правило 22, гласи: „Ония, които имат жени чрез отвличане, ако са разделили сгодени за Аруги, не трябва да се приемат в числото на каещите се, Аокато не бъдат отнети от тях (отвлечените жени) и се преАоставят на волята на Годениците им - или $А$ ги вземат, ако желаят, или да ги напуснат. А ако някой отвлече несгодена, тя трябва да бъде отнета и върната на родителите иे, били те родители, братя, или

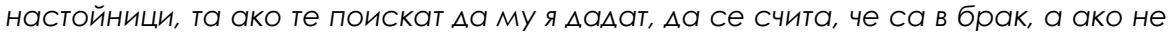
се сьгласят, нека не се принужАават. Оня, който е взел жена, която по-рано тайно или насилствено е разтлел, без Аруго трябва $А$ претьрпи църковното наказание, предвидено за блудници, което е четири години: първата година се отстраняват от молитва и п^ачат при църковните врати; на втората - се приемат да слушат писанието, на третата - стоят между каещите се, а на четвьртата стоят заедно с народа, но без да приемат свето причастие, с което отпосле нека се удостоят." 
съелинили с голениците си преди брака. ${ }^{7}$ Различния статус при жените - сголени и омъжени, не означава и различен статус при мъжете сголени и оженени (вж. по - долу) (Ivanov, 2009).

Обредьт обручение в пьрвоначалната си орорма не е с религиозна насоченост (Avxentii, 2006: р. 614). През периола VI - VIII в. чиньт е сьставен от еАна молитва и форомула, подобна на $А$ нес използваната "Обручава се Божият раб (името) в името на Отца и Сина и Светия Аух..." (Avxentii, 2006: pp. 614-615). Ао XVI - XVII в. чиньт на обручението е като отлелен самостоятелен чин (имало е и периол при който е част от утренята). За това свилетелстват преписите, в които чинът е поставен преди тайнството брак. В самите рубрики също се посочва

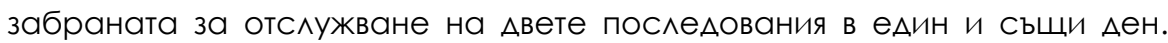
ПослеАният етап на съществуване на обручението като самостоятелно последование е запазено в Богослужебен сборник №66, съхраняван в НА - БАН. Преписът е сръбска реАакция и обхваща ^. 97а - 98а.

Началото на последованието не е запазено. Чиньт започва от Великата ектения или т. нар. Аяконства. С червенослов е отбелязана всяка еАна от началните букви от 14 - те прошения и те са: Мияони г্8

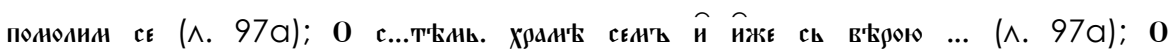

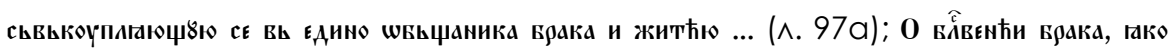
же Бь

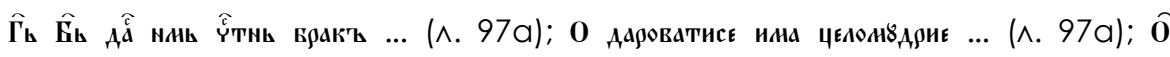

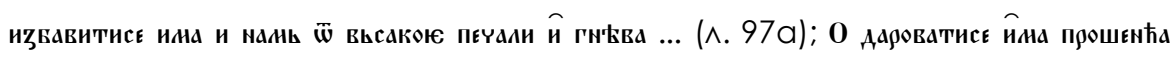

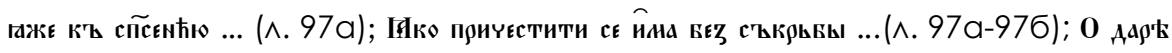

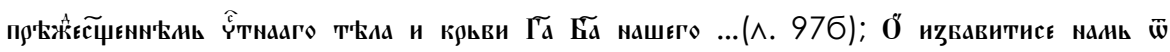

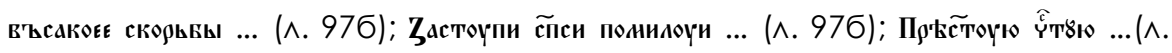
97б). С^еАващият елемент от чина е молитвата „Бжє въчнћи ...(^. 97б).

\footnotetext{
7 Из: ІІІ Каноническо послание на св. Василий Ао Амфиилохий Иконийски. Правило 22, гласи: "Ако четец се съеАини с годеницата си, преАи да е скАючил брак, слеА като се отстрани за еАна Година, Аа се приеме пак за четец, но Аа се миши от производство в по-горна степен; а ако тайно се съеАини, без да е сгоден, нека престане да служи. Същото важи и за иподякон."
} 


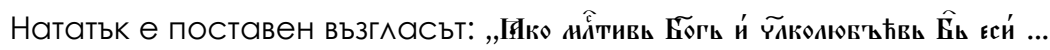
(^. 97б). СлеА тази молитва има рубрика (^. 98а), в която се обяснява, как прьстените се подават на мъжа и жената съответно златния и железния, а те от своя страна си ги разменят помежду си. Преди втората молитва от чинопоследованието свещеникът и Аяконът Изказват възГласите СъОтветно: Мияь вань ... и Главы ваше Гё́ поклоните ...(^. 98а).

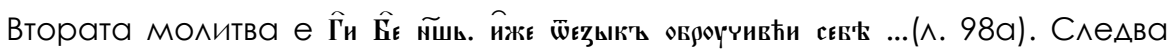
рубрика, в която се говори, че Аругата молитва на благославяне общата

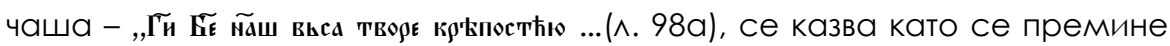
към венчанието. С червенослов е отбелязано, че ако искат $а$ с се отслужи в еАин и същи ден (обручение и венчание), то $\Delta а$ не бъле Аопускано.

В Зайковския требник последованието обхваща ^. 166 - 18 . Намира се преди тайнството брак (Tsibranska - Kostova and Mircheva, 2012). Структурата на чинът представлява: рубрика, съкратена велика

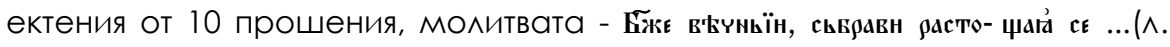

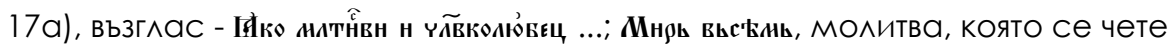

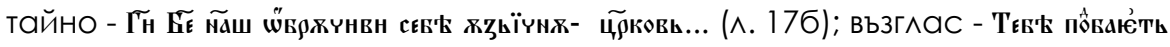

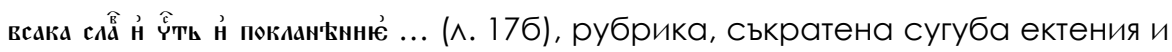
отпуст.

В това кратко чинопоследование съхранено в Зайковския требник и сборник № 66 се откриват различия. В Требника от XIV в. чиньт е отбелязан с червенослов като: Үннь на сборника от XVI в., това не може $л а$ се определи порали мипса на началните листове (Ordinary book, 2007). Останалите разлики при отлелните елементи са: Великата ектения в по - стария препис представлява 10 прошения, а Ава века слел това те са вече 13. Рела на тяхното представяне не е спазен. ЕАнакви са само 6 прошения, който се сьльржат и при Авата ръкописа, но при полредбата се наблюдава разминаване. Ннаблюдава се редакция при пьрвата молитва и в Авата преписа - Бжє втунїн, нжє

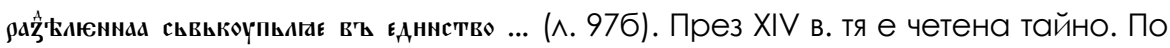
същото време и втората кратка молитва от чина е тайна. При нея се 
наблюдава също, че има редакция. В по - стария текст, тя е обградена от възгласи, а слеА това е рубрика споменаваща за размяна на прьстените.

В препис № 66 мястото на възгласите и рубриката са преди молитвата (Kodov, 1969). В същия рькопис има и Аруга молитва, която е само отбелязана, без $а$ е представен текста. Тя е за благославяне на общата чаша и рубрика с препратка $\Delta а$ се пристьпи кьм тайнството брак. Така отлелните елементи в чина очертават начина, по който е отслужен чина. C^еА XVII в. обручението се преврьща в общо последование с тайнството брак. Като причини за сливането на обручението с брака може $\Delta а$ се посочат противоречивите канонични послелици, които претърпява обрученият (сголеният, сголената) на еАно с жененият (омьжената). Например, ако сгодилият се ожени слел това за лруга смята се за втори брак, то той не може $а$ бъле ръкоположен за свещеник. За тази ангажираност на сгодените е необходимо изравняване с цьрковната Аисциплина или казано накратко необхолимо е гражданската правна система и цьрковната каноничност Аа работят в еАно за еАинството на тайнството брак. През $X$ - XI в. обручението е загубило статута си на гражАански обреА (Avxentii, 2006: р. 615). СлеА това последованието е преминало през периол, когато е извьршвано заедно с утренята и накрая слеА XVII в. то е свързано с венчанието. Тази неустановеност на чиньт обручение предполага и неговото изолиране и сливане (Avxentii, 2006: p. 615).

\section{AUTEPATYPA / REFERENCES}

Avxentii, archim. (2006). Liturgy. Plovdiv. 2006 (In Bulgarian) / [Авксентий, архим. Аитургика. П^овАив. 2006.]

Baldzhiev, V. (1891). Studios on our personal marital law. In: Collection of folk writings, science and literature. Vol. 4, p. 150-194 (In Bulgarian) / [Ба^Ажиев, В., Студия вьрху нашето персонално сьпружественно право. В: Сборник народни умотворения, наука и книжнина. Т. 4, 1891, с. 150-194]

Ivanov, Iv. (2009). Divine servants get married. A liturgical study of the sacrament of marriage, 2009, p. 51. (In Bulgarian) / [Иванов, Аяк. Ив. Венчават се божиите раби литургическо изслеАване на тайнството брак. С., 2009 г. с. 51.$]$ 
Kodov Hr. (1969). List of Slavic manuscripts in the Library of BAS, 1969. V. V. (In Bulgarian) / [КОАОв, Хр. Опис на славянските ръкописи в библиотеката на БАН. С., 1969 г. T. V.]

Nikolchev, D. (2007). Marriage, divorce and subsequent marriage in the Orthodox Church. A canonical study. S. 2007. (In Bulgarian) / [Николчев, А. Брак, разво $А$ и последващ брак в Православната цьрква. Канонично изслелване . С. 2007.]

Ordinary book, (2002). Ordinary book. Ed. St. Synod of the Bulgarian Church. S., 2002 (In Bulgarian) / [Требник. ИзА. Св. Синол на Българската цьрква. С., 2002]

Tsibranska-Kostova, Mariana; Mircheva, Elka, (2012). XIV Century Zaykov's Trebnik. Research and Text. S., 2012 (In Bulgarian) / [Цибранска - Костова Марияна, Е^ка Мирчева. Зайковски требник от XIV век Изследване и ткст. С., 2012 г.]

Volov, F. K. (1891). The Wedding Rites of the Slavic Peoples. Bulgarian Wedding Rites. In: Proceedings of Folk Works, V. V, VIII, XI, S, 1891, 1892, 1894 (In Bulgarian). I Волов, Ф. К. Свалбарскить обреди на славянскить народи Български свалбарски обреди. В: Сборник народни умотворения Т. V, VIII, XI, С., 1891, 1892, 1894.]

Volkov, K. (1891). "The Wedding Day Rites of the Slavic Peoples" Collection of Folk Mutations, Science and Literature. Vol. 5, pp. 205-232. / [K. Волковь "Сватбарскить обреди на славянскить народи" Сборник народни умотворения, наука и книжнина. Т. 5, с. 205-232.] 


\section{КУАТУРНО-ИСТОРИЧЕСКО НАСАЕАСТВО: \\ ОПАЗВАНЕ, ПРЕАСТАВЯНЕ, АИГИТААИЗАЦИЯ}

CULTURAL AND

HISTORICAL

HERITAGE

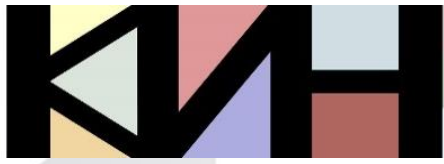

PRESERVATION PRESENTATION

DIGITIZATION
Материалите в сборника са обект на авторско право. Разрешава се безвъзмезАното ползване на техни електронни/ хартиени копия само за лична употреба или обучение, при пь^но цитиране на текущата страница и слеА писмена декларация от цитиращия за Аипса на търговски намерения. За копиране пол Аруга фрорма, препубликуване или публикуване на сървъри се изисква писмено разрешение и/или заплащане.

() Авторски колектив, 2019 Технически реАактори: Николай Ноев Калина Сотирова-Вълкова Ка^оян Николов

\section{Editors}

Galina Bogdanova Vanya Mateeva

This work is subject to copyright. Open and free of charge use of digital/hard copies of publications is granted only for personal or educational use, with full citation of the current page, and after written declaration of the quoting side for not-commercial Intention. For any other reproducing types, republishing, photocopying, recording, or any other storage retrieval system/ server written permission and/or fee is required.

(C) Authors` Group, 2019

Technical editors:

Nikolay Noev

Kalina Sotirova-Valkova

Kaloyan Nikolov

Научна поредица: том 5, брой 2 (7)/2019

Science series: vol. 5 , issue $2(7) / 2019$

www.math.bas.bg/vt/kin

ISSN: 2367-8038 